This information is current as of April 26, 2023.

\title{
Reply:
}

Mauricio Castillo and Harry J. Cloft

AJNR Am J Neuroradiol 2008, 29 (1) 5

doi: https://doi.org/10.3174/ajnr.A0760

http://www.ajnr.org/content/29/1/5.1 


\section{The Journal Formerly Known as the American Journal of Neuroradiology}

I was most interested in the commentary in the April issue of AJNR ("How American is the American Journal of Neuroradiology?") because it is hard not to notice the decreasing proportion of US articles. This commentary deserves careful reading by all academic neuroradiologists. The chart shown did not convey the magnitude of the trend. It shows that articles from the Americas represent half of the total through 2006. Using a different methodology (ie, pencil and paper), I see that there were 31 scientific articles in the February 2007 issue, and $23(74 \%)$ of these had first authors based outside of the United States. In March 2007, 24 (82\%) of 29 articles were likewise from outside of the US. This is striking because just 1 year ago in the March 2006 issue, US articles did account for 50\% of the total.

It is certainly cause for celebration that $A J N R$ has a global impact, and if it improves the quality of the science, then neuroradiologists and patients everywhere benefit. Still, one has to wonder what impact this trend will have on the US neuroradiology community. The commentary included this statement: "Academic physicians in the United States are under less pressure from their chairmen to publish, whereas those in other nations are under requirements to publish articles to qualify for promotion." ${ }^{1}$ Although I certainly agree that the pressure on academic radiologists to be clinically productive has increased at the expense of academic productivity, at the same time, I have seen no evidence that US committees on promotion are any less interested in publications. If there is only a 1 in 5 chance of getting a coveted publication slot in AJNR to start, then what will become of the new academic faculty, residents, and fellows who have had their last few articles rejected from $A J N R$, as they grapple, often daily, with their choice of academics instead of private practice?

Although I admire the journal for bringing this issue to the forefront, in my view, the commentary was lacking because it included no call to action for the US academic community. I suppose that is understandable if one thinks of AJNR now as a truly international journal and this is "just the way it is." Still, it is my hope that the US academic community will take this commentary as a wake-up call, and that we should make every effort to find the time, money, and will to improve the number and quality of our publications. I wonder if the editors of $A J N R$ feel any responsibility in this matter with regard to selection of articles. Clearly, AJNR is as American as the editors choose to make it.

\section{Reference}

1. Cloft HJ, Cloft KJ. How American Is the American Journal of Neuroradiology? AJNR Am J Neuroradiol 2007;28:601

\section{Alexander Mamourian Department of Radiology Dartmouth-Hitchcock Medical Center Lebanon, $\mathrm{NH}$}

DOI 10.3174/ajnr.A0753

\section{Reply:}

Dr Mamourian's letter reflects his uneasiness with the "internalization" of American academic imaging journals, in particular the American Journal of Neuroradiology (AJNR). He points out that AJNR contains a very high percentage $(>75 \%)$ of articles originating outside of the United States. This pattern is not unique to AJNR, and by using the same "pencil and paper" method he did, we found out that in the last 2 months, more than $50 \%$ of articles (only those labeled as "original contributions") in Radiology and more than $70 \%$ of those in the American Journal of Roentgenology (AJR) were written by foreign investigators. In an analysis of foreign articles published in the latter journal, Chen et $\mathrm{al}^{1}$ found out that, during the early 1980 s, only $10 \%$ of articles were "international," whereas in the early 2000s, this number had reached nearly $40 \%$. This is obviously a reflection of the excellent quality and reputation of American journals and their high impact factor that makes them appealing to investigators worldwide. Indeed, a recent analysis, not only of the journals with the highest impact factors but of those with the highest page ranking (a measure of the prestige of the publications), shows that AJNR, AJR, and Radiology are grouped among the world's most prestigious scientific journals. ${ }^{2}$ The Web site www.eigenfactor.org offers a ranking of scores that measure the importance of journals corrected for different citation patterns across disciplines. All of the 3 previously mentioned journals have percentile factors above 92 . Thus, we should be proud to see the number of international publications grow resulting in increased quality of our journals, and we should be ready to continue accepting them and the changes that they will bring to the more "traditional" structure of many of our scientific societies.

Dr Mamourian also issues a "wake-up call" to the American academic community to improve its number and quality of publications, and we completely agree with him. He also wonders if we, the editors of $A J N R$, feel any responsibility in the matter of article selection, as the journal can only be as American as we want it to be. He and our readership should be aware of how seriously the editors and the editorial board of AJNR take blinded peer review. Our reviewers are never aware of the origin of the articles submitted, and though their origin may be, at times, guessed by the quality of the English language used, this aspect is constantly improving, making "spotting" of international articles more difficult. We the editors do have the ability to "unblind" the articles and know their origin, but our contributors need to rest assured that nationality has never played an isolated role in their acceptance. Dr Mamourian points out that rejection of articles by junior faculty may ultimately discourage younger individuals to pursue an academic career, whereas it is our opinion that younger individuals reading high-quality articles written by foreign authors should rather be encouraged by belonging to a truly international society of investigators. The ever-increasing number of international articles in AJNR does not make it any less American, but it does makes it stronger.

\section{References}

1. Chen MY, Jenkins CB, Elster AD. Internationalization of the American Journal of Roentgenology: 1980-2002. AJR Am J Roentgenol 2003;181:907-12

2. Bollen J, Rodriguez MA, Van de Sompel H. Journal status. Scientometrics 2006;69:669-87

Mauricio Castillo Editor-in-Chief Harry J. Cloft Senior Editor

American Journal of Neuroradiology

DOI 10.3174/ajnr.A0760 